\title{
"UJI EFEKTIVITAS SALEP EKSTRAK DAUN MENGKUDU (Morinda citrifolia L.) TERHADAP LUKA SAYAT PADA KELINCI JANTAN (Oryctolagus cuniculus)"
}

\section{ACTIVITIES OF ETHANOL EXTRACT NONI LEAF (Morinda citrifolia L.) OINTMENT FOR WOUND HEALING IN MALE RABBITS (Oryctolagus cuniculus)"}

\author{
Rima Yulia Senja ${ }^{1}$, Nur Rahmi Hidayati ${ }^{1}$,Indah Setyaningsih ${ }^{1}$ \\ ${ }^{1}$ Akademi Farmasi Muhammadiyah Cirebon \\ Jl. Cideng Indah no. 3 Cirebon \\ Email:rimayuliasenja@gmail.com
}

\begin{abstract}
ABSTRAK
Daun mengkudu (Morinda cirtifolia L.) mengandung alkaloid, memiliki kemampuan sebagai anti inflamasi, antiseptik, dan antioksidan. Penelitian ini bertujuan untuk menguji efektivitas salep ekstrak etanol daun mengkudu (Morinda cirtifolia L.) terhadap pengobatan luka sayat pada kulit kelinci. Salep ekstrak etanol daun mengkudu (Morinda cirtifolia L.) diujikan pada hewan uji kelinci sebanyak 4 ekor dengan 6 perlakuan, yaitu tanpa perlakuan (kontrol normal), basis salep (kontrol negatif), salep povidon iodin (kontrol positif),salep ekstrak etanol daun mengkudu $10 \%, 15 \%$ dan $20 \%$. Area punggung kelinci disayat sepanjang $2 \mathrm{~cm}$ dengan kedalaman $\pm 0,2 \mathrm{~cm}$. Frekuensi pemberian sediaan yaitu 2 kali pengolesan setiap harinya. Pengamatan luka dilakukan setiap hari selama 14 hari. Semua data diuji secara statistik menggunakan ANOVA (Analisis Of Variant) dan dilanjutkan dengan uji LSD (LeastSignificant Different). Hasil uji statistik menunjukan adanya perbedaan terhadap lamanya penyembuhan luka pada kelinci, yaitu F hitung > F tabel $(5,271>2,77)$. Hasil statistik menggunakan metode ANOVA diperoleh kesimpulan ada perbedaan bermakna terhadap efektivitas antiluka (lama penyembuhan) antara sediaan salep ekstrak etanol daun mengkudu dengan salep povidon iodin, basis salep, dan kontrol normal.
\end{abstract}

Kata kunci $\quad$ : Salep, Daun mengkudu (Morinda cirtifolia L.), Kelinci, Luka sayat

\begin{abstract}
Noni folium (Morinda cirtifolia L.) contains alkaloids are able to provide an antiinflammatory, antiseptic, and antioxidant. The aims of this reseach were to study effectivy ofetanol Noni (Morinda cirtifolia L.) leaf extract ointment on wound healing on male rabbits. Ointment extract from Noni leaf (Morinda cirtifolia L.) tested on rabbit with 4 treatnent group, is injuries without normal control, negative control, positive control, Noni leaft oinment $10 \%, 15 \%$, and $20 \%$. All the rabbit back skin cut for $2 \mathrm{~cm}$ with depth $\pm 0,2 \mathrm{~cm}$. The wounds were applied with ointment two times daily. Observation was conducted every day for 14 day. All data was tested statistically using ANOVA (Analisis Of Variant) followed bay LSD (LeastSignificant Different). Statistical test showed that there were significabt effects on wound healing in rabbit, F count $>$ F table $(5,271>2,77)$. Statistical results using methods ANOVA conclusion no significant difference to the effectiveness of anti luka (long healing) between ointment preparation etanol noni leaft extract with povidon iodine ointment, ointment basw and normal controls.
\end{abstract}

Key words : Ointment, Noni Leaf (Morinda cirtifolia L.), Rabbit, Wound 


\section{PENDAHULUAN}

Luka adalah hilang atau rusaknya sebagian jaringan tubuh atau rusaknya kesatuan/komponen jaringan dimana secara spesifik terdapat substansi jaringan yang rusak atau hilang. Ketika luka timbul, beberapa efek akan muncul diantaranya hilangnya keseluruhan atau sebagian fungsi organ, respon stres simpatis, perdarahan dan pembekuan darah, kontaminasi bakteri dan kematian sel (Kaplan dan Hentz dalam Istiane, 2014).Sejak zaman dahulu para leluhur kita telah menggunakan tumbuh-tumbuhan sebagai penyembuh luka, salah satunya adalah tanaman mengkudu. Secara empiris, mengkudu sudah digunakan sebagai penyembuh luka (Abdul dalam Istiane, 2014).

Bagian pada tanaman mengkudu memiliki kandungan senyawa kimia yang dapat digunakan sebagai obat. Daun mengkudu mengandung alkaloid,memiliki kemampuan sebagai anti inflamasi, antiseptik, dan antioksidan(Rahmawati, 2009; Ambiyani, 2013).Penggunaan ekstrak kental secara langsung pada kulit kurang praktis dan tidak optimal, oleh karena itu perlu dibuat sediaan yang dapat menempel pada permukaan kulit dalam waktu lama, dan bersifat oklusif sehingga efektif menyembuhkan luka, yaitu sediaan semisolid dalam bentuk salep (Hernani dkk, 2012).

Penelitian Diassanti (2011) menunjukkan hasil bahwa salep ekstrak etanol daun mengkudu 15\% setelah perlakuan 4 maupun 8 hari meningkatkan epitelisasi, fibroblas, dan neovaskularisasi pada jaringan luka tikus putih wistar jantan.Penelitian yang dilakukan oleh Istiane (2014), didapatkanbahwa gel ekstrak etanol daun mengkudusecara topikal meningkatkan jumlah vaskularisasi di sekitar luka, jumlah fibroblas, dan mempercepat waktu penyembuhan luka mukosa palatum tikus galur wistar.

Pada penelitian ini akan dilakukan uji efektivitas salep ekstrak daun mengkudu terhadap luka sayat (Morinda citrifolia L.) terhadap luka sayat pada kelinci jantan (Oryctolagus cuniculus). Sediaan salep merupakan sediaan semisolid yang lunak, mudah dioleskan, dan digunakan sebagai obat luar pada kulit dan membran mukosa (Hernani dkk, 2012). Pelepasan bahan obat dalam salep sangat dipengaruhi oleh faktor fisika-kimia baik dari basis maupun dari bahan obatnya, kelarutan, viskositas, ukuran partikel, homogenitas, dan formulasi (Hernani dkk, 2012; Aryadi, 2014). Basis salep dalam penelitian ini menggunakan basis hidrokarbon, dikarenakan basis ini bersifat melunakkan lapisan kulit (emollient) karena occlusive (meninggalkan lapisan dipermukaan kulit) sehingga akan meningkatkan hidratasi kulit dengan menghambat penguapan air pada lapisan kulit. Akibat hidratasi lapisan kulit, mungkin juga akan meningkatkan aktivitas obat serta memperlama efek terapi obat. Basis hidrokarbon juga dapat digunakan untuk skin-moisturizing effect.

\section{METODE PENELITIAN \\ Alat dan Bahan}

Alat yang digunakan adalah maserator,Timbangan analitiktipe AS 160/C/2 (Radwag),Vaccum Rotary evaporator(IKA), Bisturi, Kapas (Onemed), Jangka sorong, Cotton buds. Bahan yang digunakan yaitu Daun mengkudu,Etanol 96\% (Bratachem), Parafin cair (Bratachem),Nipagin (Bratachem),Nipasol(Bratachem), Natrium metabisulfit (Bratachem),Vaselin Album(Bratachem),Salep ekstrak daun mengkudu Konsentrasi $10 \%, 15 \%$ dan $20 \%$, Salep povidon iodin (generik bermerk).

Hewan uji yang digunakan adalah kelinci jantan dengan berat masing-masing 1,5-3 $\mathrm{kg}$. Jumlah Kelinci yang digunakan sejumlah 4 ekor berdasarkan rumus Federer (t-1) (n-1) $\geq$ 15, dimana $\mathrm{t}$ menunjukan jumlah perlakuan dan $\mathrm{n}$ merupakan jumlah hewan uji tiap perlakuan. 


\section{Jalannya Penelitian}

1. Pembuatan Simplisia Kering Daun Mengkudu

Daun mengkudu dipetik kemudian disortir dan dicuci hingga bersih, lalu tiriskan. Setelah itu daun mengkdu yang sudah bersih dimasukan ke dalam oven dengan suhu $40^{\circ} \mathrm{C}$ selama 24 jam untuk proses pengeringan.

2. Pembuatan Ekstrak Daun mengkudu

Sebanyak 150 gram simplisia ditimbang dan dimasukan ke bejana, kemudian dituangi etanol 96\% sebanyak 1.125 L,ditutup, dan diaduk, serkai, peras, cuci ampas dengan cairan penyari secukupnya hingga diperoleh $1500 \mathrm{ml}$, kemudian endapan dipisahkan. Selanjutnya maserat dipekatkan dengan vaccumrotary evaporator dan dipekatkan kembali di waterbath hingga diperoleh ekstrak kental daun mengkudu.

3. Pembuatan Salep Ekstrak Etanol Daun Mengkudu

Timbang masing-masing bahan, Masukkan parafin cair dan vaselin album kedalam cawandan lebur di atas penangas air sisihkan sebagai Formula 1 (F1). Masukkan F1 kedalam mortir gerus sampai dingin dan terbentuk basis salep.Masukkan ekstrak etanol daun mengkudu sedikit demi sedikit, gerus sampai homogen.Masukkan nipagin ke dalam mortir, gerus sampai halus dan homogen.Masukkan nipasol kedalam mortir, gerus sampai halus dan homogen.Masukkan natrium metabisulfit kedalam mortir, gerus sampai halus dan homogen.Masukkan kedalam pot salep.

4. Penyiapan Hewan uji

Hewan uji diadaptasi selama dua minggu setelah itu punggung kelinci dibuat enem area perlakuan dengan lebar $2 \times 3 \mathrm{~cm}$ dan jarak antar area $2 \mathrm{~cm}$. Kemudian dilakukan pencukuran rambut kelinci pada enam area tersebut, diamkan selama semalam, dan pada keesokan harinya,pada masing-masing bagian yang sudah ditandai kemudian disayat menggunakan pisau bedah/bisturi dengan panjang $2 \mathrm{~cm}$ dengan kedalaman $\pm 0,2$ $\mathrm{cm}$ dengan cara memberi tanda pada bisturi yang telah diukur.

5. Uji efektivitas penyembuh luka

Pengujian efektivitas penyembuh luka dari salep ekstrak etanol daun mengkudu dilakukan dengan cara mengoleskan salep dua kali sekali yaitu pada pagi dan sore hari pada tiap daerah luka. Pengamatan dilakukan selama 14 hari dengan mengamati kondisi luka pada tiap area pengolesan setiap harinya. Hari pertama pengolesan dianggap hari ke-0. Luka diamati secara visual dengan melihat kondisi luka mulai dari luka mengalami inflamasi sampai luka kering dan menutup, terdapat enam perlakuan yaitu salep ekstrak etanol daun mengkudu konsentrasi 10\%, 15\%, 20\%, kontrol positif, kontrol negatif, dan kontrol normal. Kontrol positif yang digunakan adalah salep povidon iodin bermerk, kontrol negatif yang digunakan basis salep, dan kontrol normal tidak diolesi apapun. Pada tiap kelinci yang digunakan dilakukan pengacakan posisi perlakuan

\section{Analisa Data}

Evaluasi penelitian pada penyembuhan luka dilakukan dengan mengolah data secara statistik. Uji Homogenitas dan Normalitas dilakuakan dengan Uji ANOVA dilanjutkan dengan uji LSD dengan taraf kepercayaan $95 \%$.

\section{HASIL DAN PEMBAHASAN}

Penelitian ini dilakukan untuk mengetahui efektivitas salep ekstrak etanol daun mengkudu (Morinda citrifolia L.) dengan konsentrasi 10\%, 15\%, dan 20\% terhadap luka sayat pada kelinci jantan (Orytolagus cuniculus) dengan membandingkannya terhadap salep povidon iodin, basis salep, dan kontrol normal (tanpa perlakuan). Pembuatan ekstrak menggunakan cara maserasi, maserat yang diperoleh kemudian dipekatkan dengan rotary evaporator. Setelah itu diuapkan di atas penangas air hingga diperoleh ekstrak kental daun mengkudu sebanyak 29,3530 gr dan rendemen ekstrak yang dihasilkan 19,65\%.

Data hasil penelitian meliputi hasil organoleptis formula salep dari ekstrak daun 
mengkudu dapat dilihat pada tabel I dan tabel II.

Tabel I. Hasil pengamatan organoleptis salep ekstrak etanol daun mengkudu hari ke-0

\begin{tabular}{cccc}
\hline \multirow{2}{*}{ Salep } & \multicolumn{3}{c}{ Pengamatan Organoleptis } \\
\cline { 2 - 4 } & Warna & Bau & Konsistensi \\
\hline $10 \%$ & Hijau kehitaman & Bau khas daun mengkudu & Halus dan homogen \\
$15 \%$ & Hijau kehitaman & Bau khas daun mengkudu & Halus dan homogen \\
$20 \%$ & Hijau kehitaman & Bau khas daun mengkudu & Halus dan homogen \\
basis & Putih & Bau khas vaselin & Halus dan homogen \\
\hline
\end{tabular}

Berdasarkan hasil pengamatan organoleptis terhadap sediaan salep ekstrak etanol daun mengkudu (Morinda citrifolia L.) selama penyimpanan 14 hari memiliki konsistensi baik. Hasil pengamatan organoleptis terlihat warna sediaan hijau kehitaman,sediaan berbau khas daun mengkudu, dan memiliki konsistensi yang halus dan homogen. Pada basis salep warna sediaan putih, bau sediaan berbau khas vaselin, dan memiliki konsistensi yang baik dan homogen.

Tabel II.Hasil pengamatan organoleptis salep ekstrak etanol daun mengkudu hari ke14

\begin{tabular}{cccc}
\hline \multirow{2}{*}{ Salep } & \multicolumn{3}{c}{ Pengamatan Organoleptis } \\
\cline { 2 - 4 } & Warna & Bau & Konsistensi \\
\hline $10 \%$ & Hijau kehitaman & Bau khas daun mengkudu & Halus dan homogen \\
$15 \%$ & Hijau kehitaman & Bau khas daun mengkudu & Halus dan homogen \\
$20 \%$ & Hijau kehitaman & Bau khas daun mengkudu & Halus dan homogen \\
basis & Putih & Bau khas vaselin & Halus dan homogen \\
\hline
\end{tabular}

Hasil pengamatan kondisi luka yang dilakukan selama 14 hari diperoleh data dari kelompok perlakuan salep ekstrak etanol daun mengkudu 10\% dengan rata-rata sembuh dalam 5,8 hari (tabel III), kelompok salep ekstrak etanol daun mengkudu 15\% dengan rata-rata sembuh dalam 5,5 hari (tabel IV), kelompok salep ekstrak etanol daun mengkudu 20\% dengan ratarata sembuh 4,25 hari (tabel V).

Tabel III. Hasil pengamatan luka yang diolesi salep ekstrak etanol daun mengkudu konsentrasi $10 \%$

\begin{tabular}{|c|c|c|c|c|c|c|c|c|c|c|c|c|c|c|c|}
\hline \multirow{2}{*}{$\begin{array}{c}\text { Kelinci } \\
\text { Ke- }\end{array}$} & \multicolumn{14}{|c|}{ Kondisi luka pada hari ke- } & \multirow{2}{*}{$\begin{array}{c}\text { Lama } \\
\text { penyembuhan } \\
\text { (hari) }\end{array}$} \\
\hline & 1 & 2 & 3 & 4 & 5 & 6 & 7 & 8 & 9 & 10 & 11 & 12 & 13 & 14 & \\
\hline 1 & $\mathrm{Mb}$ & $\mathrm{Mb}$ & $\mathrm{M}$ & $\mathrm{Kt}$ & $\mathrm{Kt}$ & $\mathrm{Km}$ & - & - & - & - & - & - & - & - & 6 \\
\hline 2 & $\mathrm{Mb}$ & M & $\mathrm{Kt}$ & $\mathrm{Kt}$ & $\mathrm{Kt}$ & $\mathrm{Kt}$ & $\mathrm{Km}$ & - & - & - & - & - & - & - & 7 \\
\hline 3 & $\mathrm{Mb}$ & M & $\mathrm{Kt}$ & $\mathrm{Kt}$ & $\mathrm{Km}$ & - & - & - & - & - & - & - & - & - & 5 \\
\hline 4 & $\mathrm{Mb}$ & M & $\mathrm{Kt}$ & $\mathrm{Kt}$ & $\mathrm{Km}$ & - & - & - & - & - & - & - & - & - & 5 \\
\hline Jumlah & & & & & & & & & & & & & & & 23 \\
\hline Rata-rata & & & & & & & & & & & & & & & 5,8 \\
\hline
\end{tabular}




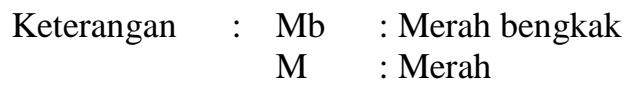

Kt $\quad$ : Kering terbuka

$\mathrm{Km}$ : Kering menutup (sembuh

Tabel IV. Hasil pengamatan luka yang diolesi salep ekstrak etanol daun mengkudu konsentrasi $15 \%$

\begin{tabular}{ccccccccccccccccc}
\hline $\begin{array}{c}\text { Kelinci } \\
\text { Ke- }\end{array}$ & 1 & 2 & 3 & 4 & 5 & 6 & 7 & 8 & 9 & 10 & 11 & 12 & 13 & 14 & $\begin{array}{c}\text { Lama } \\
\text { penyembuhan } \\
\text { (hari) }\end{array}$ \\
\hline 1 & $\mathrm{Mb}$ & $\mathrm{M}$ & $\mathrm{Kt}$ & $\mathrm{Kt}$ & $\mathrm{Kt}$ & $\mathrm{Km}$ & - & - & - & - & - & - & - & - & 6 \\
2 & $\mathrm{Mb}$ & $\mathrm{M}$ & $\mathrm{M}$ & $\mathrm{Kt}$ & $\mathrm{KM}$ & - & - & - & - & - & - & - & - & - & 5 \\
3 & $\mathrm{Mb}$ & $\mathrm{M}$ & $\mathrm{Kt}$ & $\mathrm{Kt}$ & $\mathrm{Km}$ & - & - & - & - & - & - & - & - & - & 5 \\
4 & $\mathrm{Mb}$ & $\mathrm{M}$ & $\mathrm{Kt}$ & $\mathrm{Kt}$ & $\mathrm{Kt}$ & $\mathrm{Km}$ & - & - & - & - & - & - & - & - & 6 \\
\hline Jumlah & 11 & 11 & 11 \\
\hline
\end{tabular}

Keterangan $\quad: \mathrm{Mb} \quad$ : Merah bengkak $\quad \mathrm{Kt} \quad$ : Kering terbuka

$\mathrm{M}:$ Merah $\mathrm{Km} \quad$ Kering menutup (sembuh)

Tabel V. Hasil pengamatan luka yang diolesi salep ekstrak etanol daun mengkudu konsentrasi $20 \%$

\begin{tabular}{|c|c|c|c|c|c|c|c|c|c|c|c|c|c|c|c|}
\hline \multirow{2}{*}{$\begin{array}{c}\text { Kelinci } \\
\text { Ke- }\end{array}$} & \multicolumn{14}{|c|}{ Kondisi luka pada hari ke- } & \multirow{2}{*}{$\begin{array}{c}\text { Lama } \\
\text { penyembuhan } \\
\text { (hari) }\end{array}$} \\
\hline & 1 & 2 & 3 & 4 & 5 & 6 & 7 & 8 & 9 & 10 & 11 & 12 & 13 & 14 & \\
\hline 1 & $\mathrm{Mb}$ & M & $\mathrm{Kt}$ & $\mathrm{Kt}$ & $\mathrm{Km}$ & - & - & - & - & - & - & - & - & - & 5 \\
\hline 2 & $\mathrm{Mb}$ & M & $\mathrm{Kt}$ & $\mathrm{Km}$ & - & - & - & - & - & - & - & - & - & - & 4 \\
\hline 3 & $\mathrm{Mb}$ & M & $\mathrm{Kt}$ & $\mathrm{Km}$ & - & - & - & - & - & - & - & - & - & - & 4 \\
\hline 4 & $\mathrm{Mb}$ & M & $\mathrm{Kt}$ & $\mathrm{Km}$ & - & - & - & - & - & - & - & - & - & - & 4 \\
\hline Jumlah & & & & & & & & & & & & & & & 17 \\
\hline Rata-rata & & & & & & & & & & & & & & & 4,25 \\
\hline
\end{tabular}

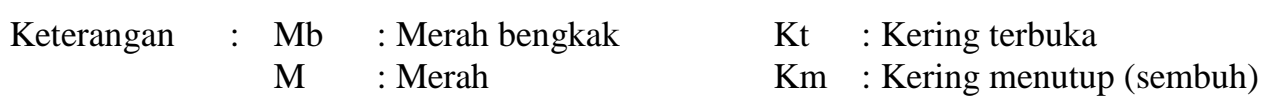

Hasil pengamatan kondisi luka yang dilakukan selama 14 hari dari kelompok salep povidon iodin dengan rata-rata sembuh 5 hari (tabel VI), kelompok basis salep dengan rata-rata sembuh 6,75 hari (tabel VII) dan kontrol normal yaitu rata-rata sembuh 7 hari (tabel VIII). 
Tabel VI. Hasil pengamatan luka yang diolesi salep povidon iodin

\begin{tabular}{|c|c|c|c|c|c|c|c|c|c|c|c|c|c|c|c|}
\hline \multirow{2}{*}{$\begin{array}{c}\text { Kelinci } \\
\text { Ke- }\end{array}$} & \multicolumn{14}{|c|}{ Kondisi luka pada hari ke- } & \multirow{2}{*}{$\begin{array}{c}\text { Lama } \\
\text { penyembuhan } \\
\text { (hari) }\end{array}$} \\
\hline & 1 & 2 & 3 & 4 & 5 & 6 & 7 & 8 & 9 & 10 & 11 & 12 & 13 & 14 & \\
\hline 1 & $\mathrm{Mb}$ & M & $\mathrm{Kt}$ & $\mathrm{Kt}$ & $\mathrm{Km}$ & - & - & - & - & - & - & - & - & - & 5 \\
\hline 2 & $\mathrm{Mb}$ & M & M & $\mathrm{Kt}$ & $\mathrm{Kt}$ & $\mathrm{Km}$ & - & - & - & - & - & - & - & - & 6 \\
\hline 3 & $\mathrm{Mb}$ & M & $\mathrm{Kt}$ & $\mathrm{Km}$ & - & - & - & - & - & - & - & - & - & - & 4 \\
\hline 4 & $\mathrm{Mb}$ & M & $\mathrm{Kt}$ & $\mathrm{Kt}$ & $\mathrm{Kt}$ & $\mathrm{Km}$ & - & - & - & - & - & - & - & - & 5 \\
\hline Jumlah & & & & & & & & & & & & & & & 20 \\
\hline Rata-rat & & & & & & & & & & & & & & & 5 \\
\hline Keterang & & 1 & & $\begin{array}{l}\text { Mera } \\
\text { Mera }\end{array}$ & $\begin{array}{l}h \text { ben } \\
h\end{array}$ & kak & & & $\begin{array}{l}\mathrm{Kt} \\
\mathrm{Km}\end{array}$ & $: 1$ & Cerin & $\begin{array}{l}\mathrm{g} \text { ter } \\
\mathrm{g} \mathrm{me}\end{array}$ & $\begin{array}{l}\text { puka } \\
\text { nutup }\end{array}$ & ( $\mathrm{sel}$ & buh) \\
\hline
\end{tabular}

Tabel VII. Hasil pengamatan luka yang diolesi basis salep

\begin{tabular}{|c|c|c|c|c|c|c|c|c|c|c|c|c|c|c|c|}
\hline \multirow{2}{*}{$\begin{array}{c}\text { Kelinci } \\
\text { Ke- }\end{array}$} & \multicolumn{14}{|c|}{ Kondisi luka pada hari ke- } & \multirow{2}{*}{$\begin{array}{c}\text { Lama } \\
\text { penyembuhan } \\
\text { (hari) }\end{array}$} \\
\hline & 1 & 2 & 3 & 4 & 5 & 6 & 7 & 8 & 9 & 10 & 11 & 12 & 13 & 14 & \\
\hline 1 & $\mathrm{Mb}$ & $\mathrm{Mb}$ & $\mathrm{Mb}$ & M & Kt & $\mathrm{Kt}$ & $\mathrm{Kt}$ & $\mathrm{Km}$ & - & - & - & - & - & - & 8 \\
\hline 2 & $\mathrm{Mb}$ & $\mathrm{Mb}$ & $\mathrm{Mb}$ & M & $\mathrm{Kt}$ & $\mathrm{Kt}$ & $\mathrm{Km}$ & - & - & - & - & - & - & - & 7 \\
\hline 3 & $\mathrm{Mb}$ & M & $\mathrm{Kt}$ & $\mathrm{Kt}$ & $\mathrm{Km}$ & - & - & - & - & - & - & - & - & - & 5 \\
\hline 4 & $\mathrm{Mb}$ & $\mathrm{Mb}$ & M & $\mathrm{Kt}$ & $\mathrm{Kt}$ & $\mathrm{Kt}$ & $\mathrm{Km}$ & - & - & - & - & - & - & - & 7 \\
\hline Jumlah & & & & & & & & & & & & & & & 27 \\
\hline Rata-rata & & & & & & & & & & & & & & & 6,75 \\
\hline Keteran & & $\Lambda$ & & $\begin{array}{l}\text { Mer } \\
\text { Mer }\end{array}$ & & kak & & & $\mathrm{m}$ & & $\begin{array}{l}\text { ring } \\
\text { ring }\end{array}$ & $\begin{array}{l}\text { terbu } \\
\text { menu }\end{array}$ & & sem & \\
\hline
\end{tabular}

Tabel VIII.Hasil pengamatan luka tanpa perlakuan

\begin{tabular}{|c|c|c|c|c|c|c|c|c|c|c|c|c|c|c|c|}
\hline \multirow{2}{*}{$\begin{array}{c}\text { Kelinci } \\
\text { Ke- }\end{array}$} & \multicolumn{14}{|c|}{ Kondisi luka pada hari ke- } & \multirow{2}{*}{$\begin{array}{c}\text { Lama } \\
\text { penyembuhan } \\
\text { (hari) }\end{array}$} \\
\hline & 1 & 2 & 3 & 4 & 5 & 6 & 7 & 8 & 9 & 10 & 11 & 12 & 13 & 14 & \\
\hline 1 & $\mathrm{Mb}$ & $\mathrm{Mb}$ & $\mathrm{Mb}$ & M & M & $\mathrm{Kt}$ & $\mathrm{Km}$ & - & - & - & - & - & - & - & 7 \\
\hline 2 & $\mathrm{Mb}$ & $\mathrm{Mb}$ & $\mathrm{Mb}$ & M & $\mathrm{Kt}$ & $\mathrm{Kt}$ & $\mathrm{Km}$ & - & - & - & - & - & - & - & 7 \\
\hline 3 & $\mathrm{Mb}$ & $\mathrm{M}$ & $\mathrm{Kt}$ & $\mathrm{Kt}$ & $\mathrm{Kt}$ & $\mathrm{Km}$ & - & - & - & - & - & - & - & - & 6 \\
\hline 4 & $\mathrm{Mb}$ & $\mathrm{Mb}$ & $\mathrm{Mb}$ & $\mathrm{M}$ & $\mathrm{Kt}$ & $\mathrm{Kt}$ & $\mathrm{Kt}$ & $\mathrm{Km}$ & - & - & - & - & - & - & 8 \\
\hline Jumlah & & & & & & & & & & & & & & & 28 \\
\hline Rata-rata & & & & & & & & & & & & & & & 7,0 \\
\hline Keterang & & $:$ & & $\begin{array}{l}\text { : Mer } \\
: \text { Mer }\end{array}$ & & D & & & $\begin{array}{l}\mathrm{Kt} \\
\mathrm{Km}\end{array}$ & & ring & menu & $\begin{array}{l}\text { ka } \\
\text { atup }\end{array}$ & (semb & \\
\hline
\end{tabular}


Data yang diperoleh kemudian dilakukan pengujian normalitas dan homogenitas. Hasilujinormalitasdidapatkannilai $\mathrm{P}=0,363>0,05$ yang berarti data tersebutterdistribusi normal, hasilujihomogenitasdidapatkannilai $\mathrm{P}=0,633>0,05$ yang berarti data tersebuthomogen, sehingga dapat dilakukan analisis parametik dengan metode ANOVA (Analisis of Varians).

Data yang telah diolah secara statistik dengan menggunakan metode ANOVA (Analisis of Varians) untuk membandingkan 6 kelompok perlakuan (tabel IX). Hasil statistik dengan menggunakan metode ANOVA dengan menggunakan uji $\mathrm{F}$ menunjukan nilai $\mathrm{F}$ hitung sebesar 5,271 dan signifikan 0,004,sedangkan nilai $F$ tabel sebesar 2,77. Nilai $F$ hitung lebih besar dari $\mathrm{F}$ tabel $(5,271>2,77)$ sehingga dapat disimpulkan ada perbedaan yang signifikan antara kelompok ekstrak etanol daun mengkudu (Morinda citrifolia L.), kelompok salep povidon iodin (kontrol positif), kelompok basis salep (kontrol negatif), dan kelompok tanpa perlakuan (kontrol normal).

\section{Tabel IX. Hasil tes LSD}

\begin{tabular}{lll}
\hline Kelompok & Hasil analisa & Kesimpulan \\
\hline salep 10\% - salep 15\% & $\mathrm{p}=0,693>0,05$ & Tidak berbeda bermakna \\
salep 10\% - salep 20\% & $\mathrm{p}=0,027>0,05$ & Berbeda bermakna \\
salep 10\% - salep povidon iodin & $\mathrm{p}=0,433>0,05$ & Tidak berbeda bermakna \\
salep 10\% - Basis salep & $\mathrm{p}=0,126>0,05$ & Tidak berbeda bermakna \\
salep 10\% - tanpa perlakuan & $\mathrm{p}=0,060>0,05$ & Tidak berbeda bermakna \\
salep 15\% - salep 20\% & $\mathrm{p}=0,060>0,05$ & Tidak berbeda bermakna \\
salep 15\% - salep povidon iodin & $\mathrm{p}=0,693>0,05$ & Tidak berbeda bermakna \\
salep 15\% - basis salep & $\mathrm{p}=0,060>0,05$ & Tidak berbeda bermakna \\
salep 15\% - tanpa perlakuan & $\mathrm{p}=0,027<0,05$ & Berbeda bermakna \\
salep 20\% - salep povidon iodin & $\mathrm{p}=0,126>0,05$ & Tidak berbeda bermakna \\
salep 20\% - basis salep & $\mathrm{p}=0,001<0,05$ & Berbeda bermakna \\
salep 20\% - tanpa perlakuan & $\mathrm{p}=0,000<0,05$ & Berbeda bermakna \\
salep povidon iodin - basis salep & $\mathrm{p}=0,027<0,05$ & Berbeda bermakna \\
salep povidon iodin - tanpa perlakuan & $\mathrm{p}=0,027<0,05$ & Berbeda bermakna \\
basis salep - tanpa perlakuan & $\mathrm{p}=0,693>0,05$ & Tidak berbeda bermakna \\
\hline
\end{tabular}

Dari penjelasan di atas didapatkan bahwaperlakuan pada kontrol normal (tanpa perlakuan) memberikan efek penyembuhan paling lama dalam proses penyembuhan luka jika dibandingkan dengan perlakuan lain. Ini disebabkan pada kontrol normal tidak diberikan perlakuan apapun yang menyebabkan kemungkinan masuknya kuman yang menginfeksi luka sehingga terjadi proses penyembuhan luka yang relatif lama. Efek penyembuhan luka pada kontrol negatif (basis salep) masih memberikan efek menyembuhkan luka akan tetapi lebih lambat jika dibandingkan dengan kontrol positif (salep povidon iodin) dan salep ekstrak etanol daun mengkudu, hal ini disebabkan pada kontrol negatif tidak terdapat zat aktif dari ekstrak daun mengkudu karena hanya menggunakan dasar salep yang berfungsi sebagai penutup luka tanpa memberikan efek penyembuhan yang berarti. Efek penyembuhan luka pada kontrol positif (salep povidon iodin) memiliki kemiripan penyembuhan luka yang sama dengan salep ekstrak etanol daun mengkudu 15\% sedangkan efek penyembuhan pada salep ekstrak daun mengkudu 10\% sedikit lebih lambat jika dibandingkan dengan kontrol positif dan salep ekstrak etanol daun mengkudu 15\%. Tetapi salep ekstrak etanol daun mengkudu $10 \%$ masih memberikan efek penyembuhan lebih cepat jika dibandingkan dengan kontrol negatif (basis salep) dan kontrol normal (tanpa perlakuan), hal ini disebabkan pada salep ekstrak etanol daun mengkudu 10\% terdapat zat aktif yang memiliki efek sebagai 
penyembuh luka dengan jumlah hari yang sedikit, walaupun uji statistik menunjukan tidak ada berbeda bermakna. Proses penyembuhan luka pada salep ekstrak etanol daun mengkudu $20 \%$ memiliki efek menyembuhkan luka yang sangat cepat jika dibandingkan dengan salep ekstrak etanol daun mengkudu karena pada salep ekstrak etanol daun mengkudu $20 \%$ terkandung lebih banyak zat aktif yang dapat membantu proses penyembuhan luka lebih cepat. Peningkatan konsentrasi ekstrak efektivitas antiluka semakin bagus.

\section{KESIMPULAN}

Ekstrak etanol daun mengkudu efektif dalam penyembuhan luka sayat pada kelinci jantan. Lama penyembuhan luka sayat pada area yang diolesi salep ekstrak etanol $20 \%$ relatif lebih cepat menyembuhkan luka sayat pada kelinci jantan dibandingkandenganarea yang diolesi salep ekstrak etanol daun mengkudu 15\% dan area yang diolesi salep ekstrak etanol daun mengkudu $10 \%$.

\section{DAFTAR PUSTAKA}

Ambiyani, W. 2013. Pemberian Salep Ekstrak Daun Mengkudu (Morinda citrifolia L) Meningkatkan Proses Regenerasi Jaringan Pada Tikus Putih Galur Wistar (Rattus norvegicus) Jantan. Bogor: Universitas Undayana.

Aryadi,I. 2014.Pengaruh Ekstrak Daun Mengkudu (Morinda citrifolia L.) Terhadap Pertumbuhan Staphylococcus aureus Sebagai Penyebab Abses Periodontal Secara In Vitro.Skripsi pada Fakultas Kedokteran Gigi Universitas Mahasaraswati Denpasar: tidak diterbitkan

Diassanti, A. 2011.Uji Ekstrak Etanol Daun Mengkudu (Morinda citrifolia) Sebagai Antimikroba Terhadap Methicillin-resistant Staphylococcus aureus (MRSA) Secara Invitro. Malang: Fakultas Kedokteran Universitas Brawijaya

Hernani, M. Y, Mufrod, Sugiyono, 2012. Formulasi Salep Ekstrak Air Tokek(Gekko gecko L.) untuk penyembuhan luka. Majalah Farmaseutik, vol 8 No 1.

Istiane,F.2014.Pengaruh Gel Estrak Etanol Daun Mengkudu Terhadap Penyembuhan Luka Mukosa Palatum Tikus Galur Wistar.Bionatura:Jurnal Ilmu-Ilmu Hayati dan Fisik, 16 (3), 159-162

Rahmawati, A. 2009. Kandungan Fenol Daun Mengkudu Sebagai Antioksidan. Depok: Fakultas Kedokteran UI 